\title{
The Ability to Achieve a Specific Target Angle on Weightbearing Radiographs After Valgus High Tibial Osteotomy for Medial Knee Arthritis Is Not Predictable
}

\author{
G. Klaud Miller, M.D., Agnes Maddox, R.N., and Sandra El-Daccache, B.S.
}

\begin{abstract}
Purpose: Standing radiographs are commonly used to plan angular correction in valgus tibial osteotomy for varus gonarthrosis. Most clinical studies have reported postoperative alignment as overall averages or means. The purpose of this study was to compare the preoperatively planned angle of correction measured on weight-bearing radiographs to the follow-up angle measured on weightbearing radiographs in individual patients 6 weeks after surgery and to analyze factors that could potentially affect achieving the planned degree of surgical correction. Our objective was to analyze factors potentially affecting the accuracy and ability to achieve the preoperatively planned correction angle (the target angle) in the individual patient. Methods: We studied 35 tibial osteotomies (13 Coventry closing wedge osteotomies and 22 Maquet barrel vault osteotomies) performed for varus gonarthrosis between 1981 and 2019 to determine how accurately the target angle, based on preoperative standing weight-bearing radiographs, was achieved according to the postoperative radiographs in each individual. We reviewed 35 knees in 34 patients who had complete pre- and postoperative radiographs for review. Results: Overall, only 14 of $35(40 \%)$ of the patients were corrected to within $\pm 2^{\circ}$ of the planned target angle. Valgus tibial osteotomy based on preoperative weightbearing radiographs is unpredictable in its ability to achieve the target angle on postoperative weightbearing radiographs when using either the Coventry or the Maquet surgical technique. The tendency was to undercorrect with either of the techniques. Larger (greater than $10^{\circ}$ ) preoperative varus alignment did not make it more difficult to achieve the target angle. Male or female sex and body mass index had no effect on the ability to achieve the target angle. Conclusions: Valgus tibial osteotomy planning based on preoperative weightbearing is unpredictable in its ability to achieve the target angle on postoperative weightbearing radiographs. Overall, only $40 \%$ of our patients were corrected to within $\pm 2^{\circ}$ of the planned target angle. The tendency was to undercorrect, with either the Coventry or the Maquet technique. Contrary to our hypothesis, larger preoperative varus alignment (greater than $10^{\circ}$ ) did not make it more difficult to achieve the target angle. The Coventry technique was as accurate as the Maquet technique. Level of Evidence: Level IV.
\end{abstract}

$\mathbf{T}$ ibial osteotomy is most commonly performed to treat medial compartment arthritis with varus alignment to reestablish anatomic valgus alignment of the knee. The purpose of a valgus tibial osteotomy is to

From Windy City Orthopedics and Sports Medicine, Chicago, Illinois, U.S.A. The authors report no conflicts of interest in the authorship and publication of this article. Full ICMJE author disclosure forms are available for this article online, as supplementary material.

Received October 8, 2019; accepted February 25, 2020

Address correspondence to G. Klaud Miller M.D., Windy City Orthopedics and Sports Medicine, 2617 W. Peterson Ave., Chicago, Illinois 60659. Tel: 847-475-0200.E-mail:Doc@jockdoc.net

(C) 2020 THE AUTHORS. Published by Elsevier Inc. on behalf of the Arthroscopy Association of North America. This is an open access article under the CC BY-NC-ND license (http://creativecommons.org/licenses/by-nc-nd/4.0/). 2666-061X/191196

https://doi.org/10.1016/j.asmr.2020.02.010 surgically alter the alignment of the leg to dynamically unload the medial compartment. Several studies have shown that the clinical success rate of tibial osteotomy is very successful in the short-term and midterm timeframes if "adequate angular correction," as defined by various authors over the years (Table 1$),{ }^{1-20}$ is achieved, but results tend to deteriorate with time. The clinical results have been much less successful if "adequate" valgus correction is not achieved. Coventry ${ }^{3}$ stated that 10-year survival was $94 \%$ if the postoperative anatomic valgus was greater than or equal to $8^{\circ}$ but only $63 \%$ if there were only $5^{\circ}$ of anatomic valgus. Regardless of the specific surgical technique, inherent in any surgical technique is preoperative planning to determine the size of the correction. Multiple recommendations have been made in the literature regarding the degree of correction necessary to 
Table 1. Recommended Postop Target Angles

\begin{tabular}{lcc}
\hline \multicolumn{1}{c}{ Study } & Year & Recommendation \\
\hline Anatomic Axis Alignment & & $5^{\circ}$ \\
Shoji $^{1}$ & 1973 & $10^{\circ}$ \\
Insall $^{2}$ & 1984 & $8^{\circ}$ \\
Coventry $^{3}$ & 1993 & $10^{\circ}$ \\
Akamatsu $^{4}$ & 1997 & $10^{\circ}$ \\
Aglietti $^{5}$ & 2003 & $8^{\circ}-16^{\circ}$ \\
Sprenger $^{6}$ & 2003 & $10^{\circ}$ \\
Koshino $^{7}$ & 2004 & $8^{\circ}-10^{\circ}$ \\
Huang $^{8}$ & 2005 & $6^{\circ}$ \\
Flecher $^{9}$ & 2006 & $10^{\circ}$ \\
Puddu $^{10}$ & 2007 & $10^{\circ}$ \\
Akizuki $^{11}$ & 2008 & $10^{\circ}$ \\
Howells $^{12}$ & 2014 & \\
Mechanical axis alignment $^{\circ}$ & & $2^{\circ}-4^{\circ}$ \\
Maquet $^{13}$ & 1976 & $3^{\circ}$ \\
Krempen $^{14}$ & 1982 & $4^{\circ}$ \\
Brower $^{15}$ & 2006 & \\
62.5\% of the medial-to-lateral width of the proximal tibia \\
alignment $_{\text {Dugdale }}^{16}$ & & \\
Aoki $^{17}$ & 1992 & \\
Bae & 2006 & \\
Lee $^{19}$ & 2009 & \\
Kondo $^{20}$ & 2012 & \\
\hline
\end{tabular}

achieve "adequate" postoperative valgus alignment (Table 1). ${ }^{1-20}$

Most series in the literature report only averages, means or ranges of postoperative alignment. It seems logical to assume that if a surgeon fails to achieve "adequate" correction, "inadequate" correction could adversely affect clinical results. The purpose of this study was to compare the preoperatively planned angle of correction as measured on weight-bearing radiographs to the follow-up angle as measured on weight-bearing radiographs in each individual patient 6 weeks after surgery and to analyze factors that could potentially affect achieving the planned degree of surgical correction. Our hypothesis was that it would be more difficult to achieve the preoperatively planned correction with larger body mass indexes (BMIs) and larger degrees of preoperative varus and that the Coventry "closing wedge" surgical technique would be less accurate than the Maquet "barrel vault" surgical technique.

\section{Methods}

Between 1981 and 2019, 65 knees in 64 patients were scheduled for valgus tibial osteotomies performed using either the Coventry ${ }^{3}$ and, later on, the Maquet ${ }^{13,21}$ surgical technique. Complete pre- and postoperative radiographs were available for 34 patients and 35 knees. The target angles were prospectively determined based on standard standing anteroposterior radiographs of both knees, with the knees fully extended, taken on $14 \times 17$ radiographs. ${ }^{18}$ The radiographs were taken both preoperatively and postoperatively and without any external support. The limb alignment was measured on each radiograph by using the anatomic axis method by the senior surgeon (GKM). Full-length mechanical axis films were taken in several cases, but the size of correction was the same whether the anatomic or mechanical axis was used. This is consistent with all knee literature. ${ }^{22,23}$ Therefore, for purposes of the study, only the anatomic axis was used to determine prospectively the planned correction.

We arbitrarily defined anatomic varus alignment as negative angles and anatomic valgus as positive angles. We defined the preoperative angle as the anatomic axis angle measured on the preoperative radiographs. We defined the target angle as the anatomic axis angle that we prospectively planned to achieve during surgery. We defined the planned correction as the difference between the preoperative angle and the target angle. We defined the postoperative angle as the anatomic axis angle measured on the radiographs taken 6 weeks after surgery. We defined the actual correction as the difference between the preoperative angle and the postoperative angle. We defined the error in correction as the difference between the postoperative angle and the planned correction.

Based on the preoperative radiographs, the anatomy of the knee, the gender, and the preoperative angle, surgical correction was individually and prospectively planned by the senior operating surgeon (i.e., the target angle). The target angle was most commonly $5^{\circ}-8^{\circ}$ of anatomic valgus in males and $8^{\circ}-10^{\circ}$ of valgus in females. To allow for healing of the osteotomy so that the patient could be weightbearing without external support, the anatomic axis (i.e., the postoperative angle) was measured on the standing radiographs taken 6 weeks after surgery using the same radiologic technique.

\section{Surgical Technique}

The closing wedge osteotomy technique was performed as using the Coventry technique. ${ }^{1}$ The barrel vault osteotomy technique was performed as reported by Miller $^{17}$ and Maquet. ${ }^{2}$

\section{Results}

There were 35 knees ( 12 males [ 1 bilateral] and 22 females with prospectively measured alignment and complete preoperative and postoperative radiographs (Table 2). Because some patients had tibial osteotomies performed in the same time frame but did not have complete preoperative and postoperative radiographs available for review, this was not a consecutive series. There were 19 right knees and 16 left knees. The average age was 58 (range 35-68), and the average BMI was 34.7 (range 21.2-58.2). There were 13 Coventry closing wedge osteotomies and 22 Maquet barrel vault osteotomies ( 1 bilateral in a male). All patients were 
Table 2. Baseline Study Data

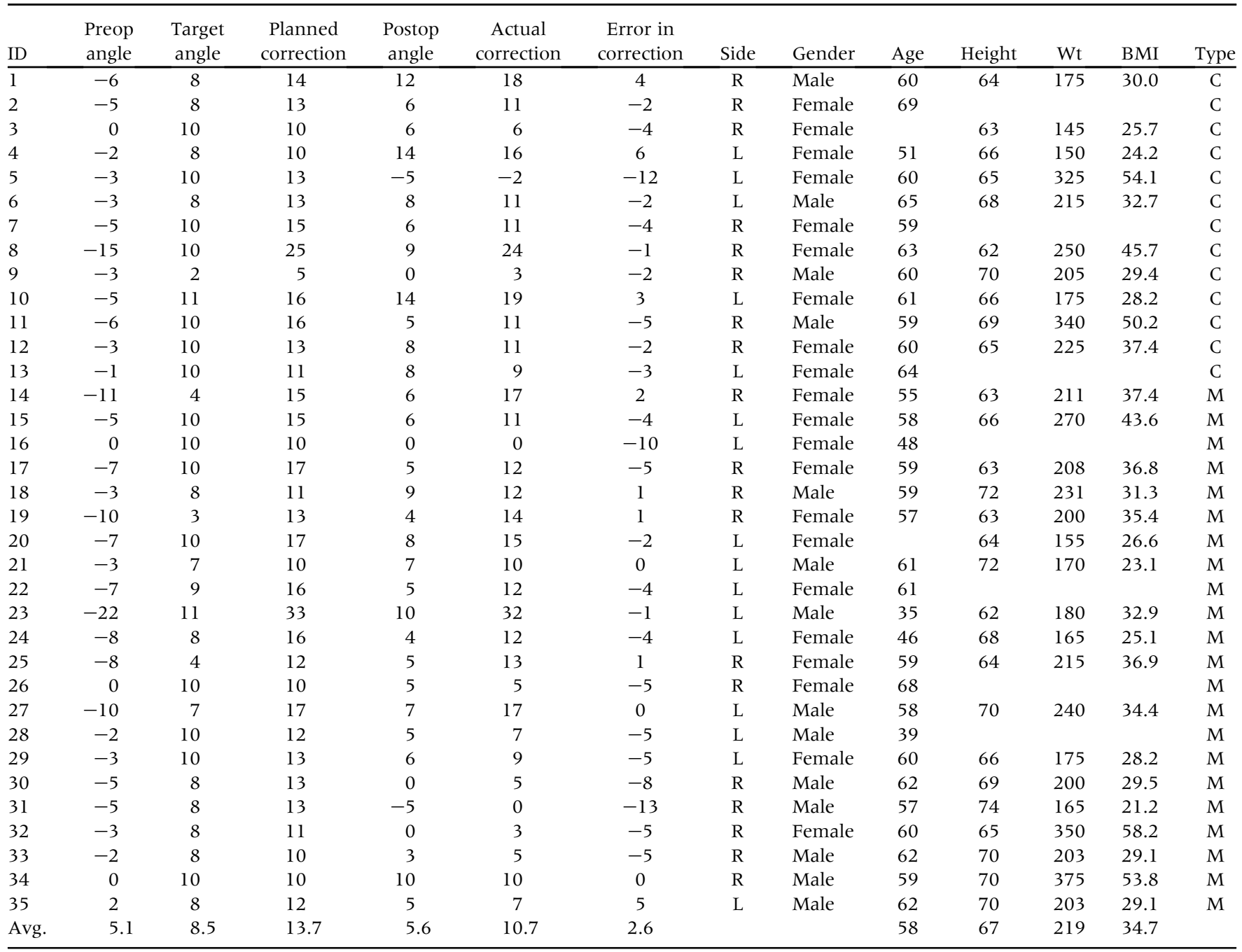

fully weightbearing without external support 6 weeks after surgery.

The preoperative angle (Fig 1) in 35 knees averaged $-5.1^{\circ}$ (i.e., $5.1^{\circ}$ of varus-range, $22^{\circ}$ of varus-to-neutral alignment). The target angle in 35 knees averaged $8.5^{\circ}$ (range $2^{\circ}-11^{\circ}$ of valgus). The planned correction in 35 knees averaged $13.7^{\circ}$ (range $5^{\circ}-25^{\circ}$ ). The postoperative angle averaged $5.6^{\circ}$ of valgus (range $0^{\circ}-10^{\circ}$ ). There were 7 knees that were overcorrected by an average of $2.8^{\circ}$ (range $\left.1^{\circ}-6^{\circ}\right), 3$ knees that were corrected to exactly the target angle, and 24 knees that were undercorrected by an average of $3.4^{\circ}$ (range $-1^{\circ}$ to $\left.-13^{\circ}\right)$. In the group of 24 patients with undercorrected angles, there were 2 with no change from the preoperative angles (ID \#16 and \#31, both Maquet osteotomies), and 1 patient actually had an increase in the preoperative varus alignment by $2.0^{\circ}$ (ID \#5, a Coventry osteotomy). Overall, only 14 of $35(40.0 \%)$ of the knees were corrected to within $\pm 2^{\circ}$ of the target angle.
In the 13 knees treated by the Coventry technique (Fig 2 ), the preoperative angle averaged $-4.4^{\circ}$ (i.e., $4.4^{\circ}$ of varus, range $15^{\circ}$ of varus to neutral alignment). The target angle in 13 knees averaged $8.8^{\circ}$ (range $2^{\circ}-11^{\circ}$ of valgus). The planned correction averaged $13.2^{\circ}$ (range $5^{\circ}-25^{\circ}$ ). The postoperative angle averaged $7.0^{\circ}$ of valgus (range $0^{\circ}-14^{\circ}$ ). There were 3 knees that were overcorrected by an average of $4.3^{\circ}$ (range $3^{\circ}-6^{\circ}$ ), No knees were corrected to exactly the target angle, and 10 knees were undercorrected by average of $3.7^{\circ}$ (range $-1^{\circ}$ to $\left.-12^{\circ}\right)$. One patient actually had an increase in preoperative varus alignment by $2.0^{\circ}$ (ID \#5). Overall, only 5 of $13(38.5 \%)$ knees were corrected to within $\pm 2^{\circ}$ of the target angle.

In the 22 knees that underwent the Maquet technique (Fig 3), the preoperative angle averaged $-5.6^{\circ}$ (i.e., $5.6^{\circ}$ of varus range, $22^{\circ}$ of varus-to-neutral alignment). The target angle in 22 knees averaged $8.2^{\circ}$ (range $4^{\circ}-11^{\circ}$ of valgus). The planned correction averaged $13.8^{\circ}$ (range $5^{\circ}-25^{\circ}$ ). The postoperative 


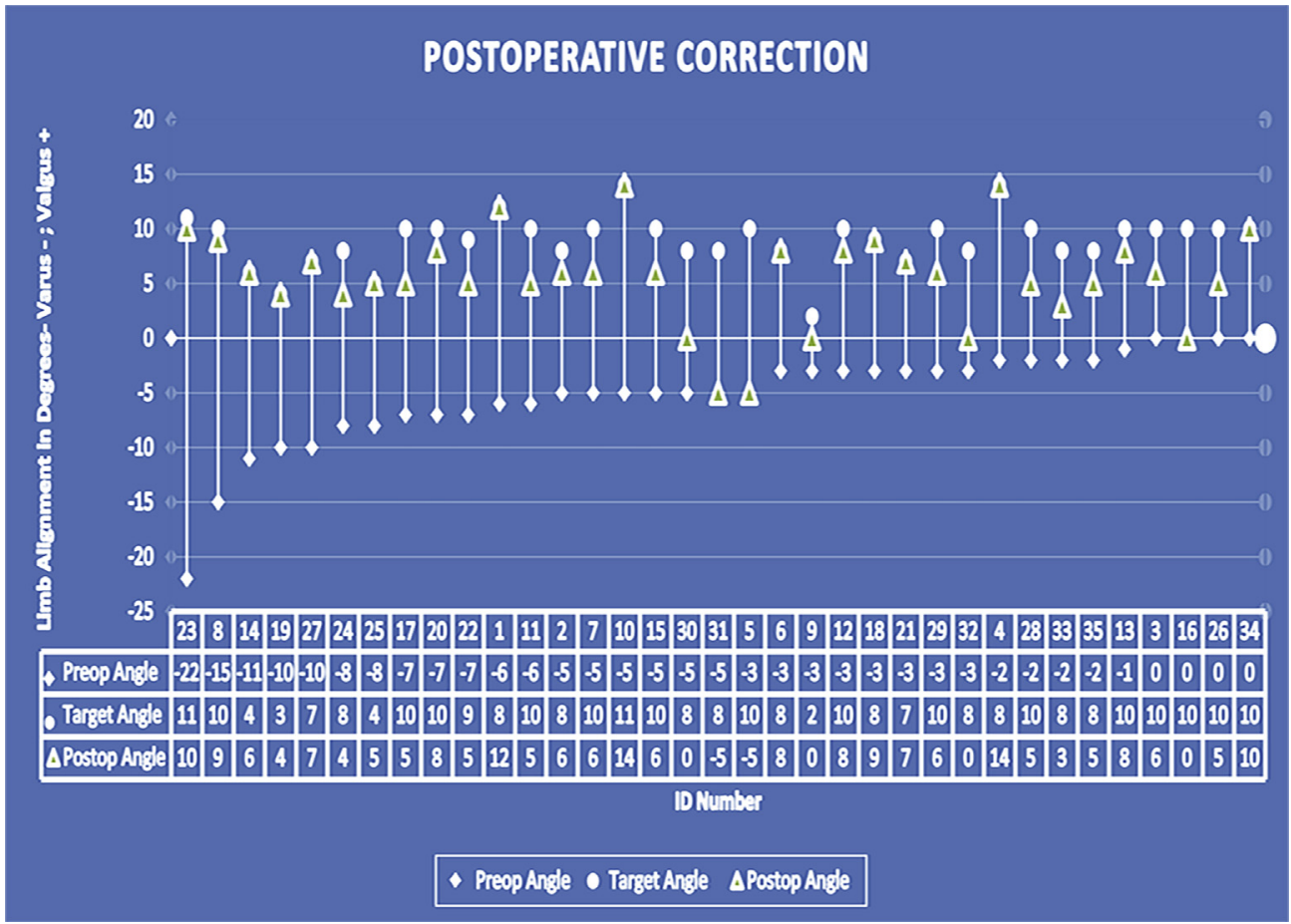

Fig 1. Postoperative correction, overall. Target angle, the prospectively planned valgus angle. Preoperative and postoperative angles. The angles measured on the preoperative and postoperative radiographs.

angle averaged $4.8^{\circ}$ of valgus (range $-5^{\circ}$ to $14^{\circ}$ ). There were 4 knees that were overcorrected by an average of $1.25^{\circ}$ (range $\left.1^{\circ}-2^{\circ}\right), 3$ knees that were corrected to exactly the target angle, and 15 knees that were undercorrected by an average of $4.9^{\circ}$ (range $-1^{\circ}$ to $\left.-13^{\circ}\right)$. No patient had an increase in preoperative varus alignment after surgery. Overall, only 8 of $22(36.4 \%)$ of the knees were corrected to within $\pm 2^{\circ}$ of the target angle.

In the 21 females (Fig 4), the preoperative angle averaged $-5.1^{\circ}$ (i.e., $5.1^{\circ}$ of varus range, $15^{\circ}$ of varusto-neutral alignment). The target angle in 21 knees averaged $8.7^{\circ}$ (range $4^{\circ}-10^{\circ}$ of valgus). The planned correction averaged $13.9^{\circ}$ (range $10^{\circ}-25^{\circ}$ ). The
Fig 2. Coventry postoperative correction. Tibial osteotomies performed using the Coventry technique. Target angle, the prospectively planned valgus angle. Preop and postop angles, the angles measured on the preoperative and postoperative radiographs.

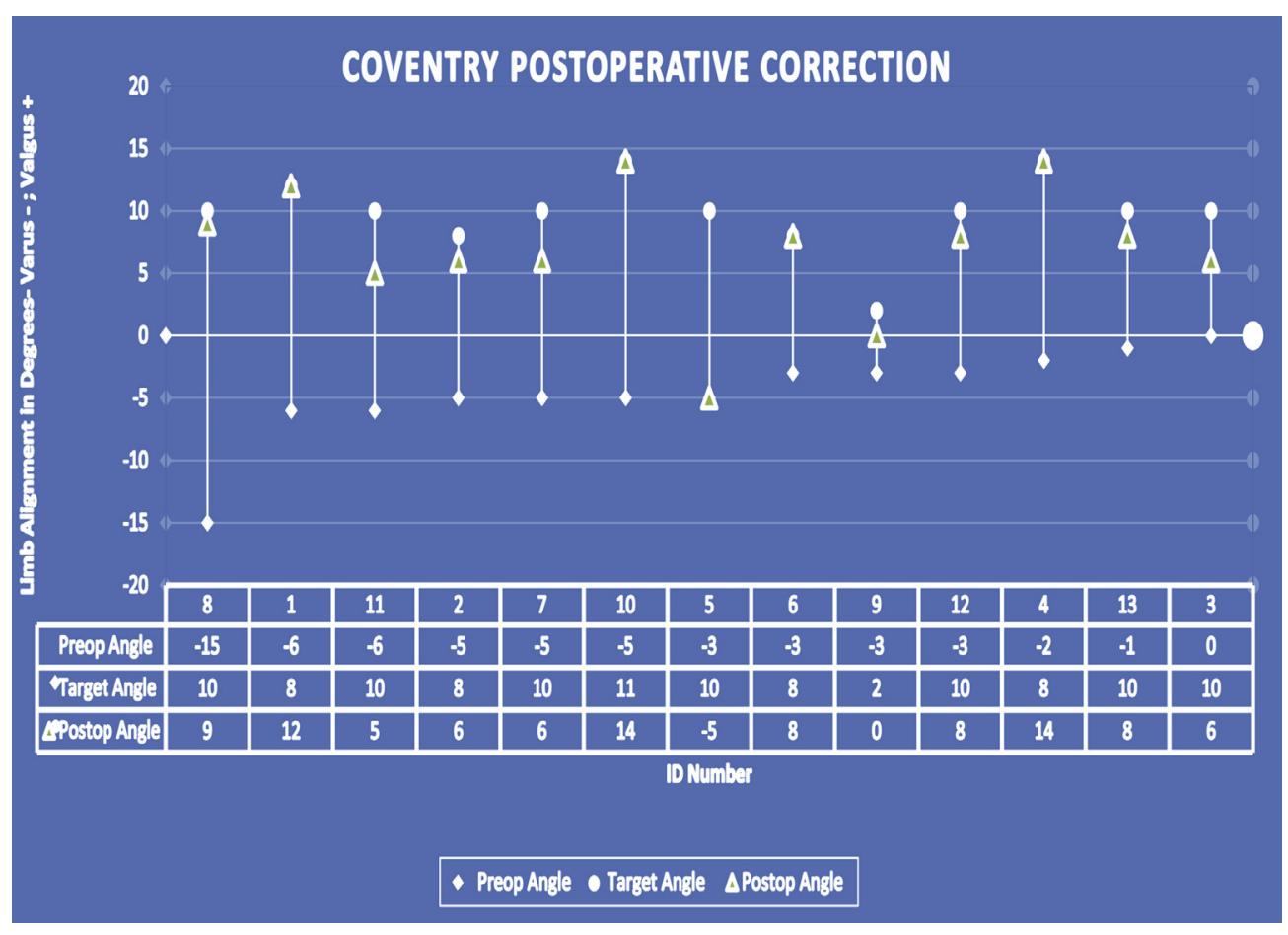




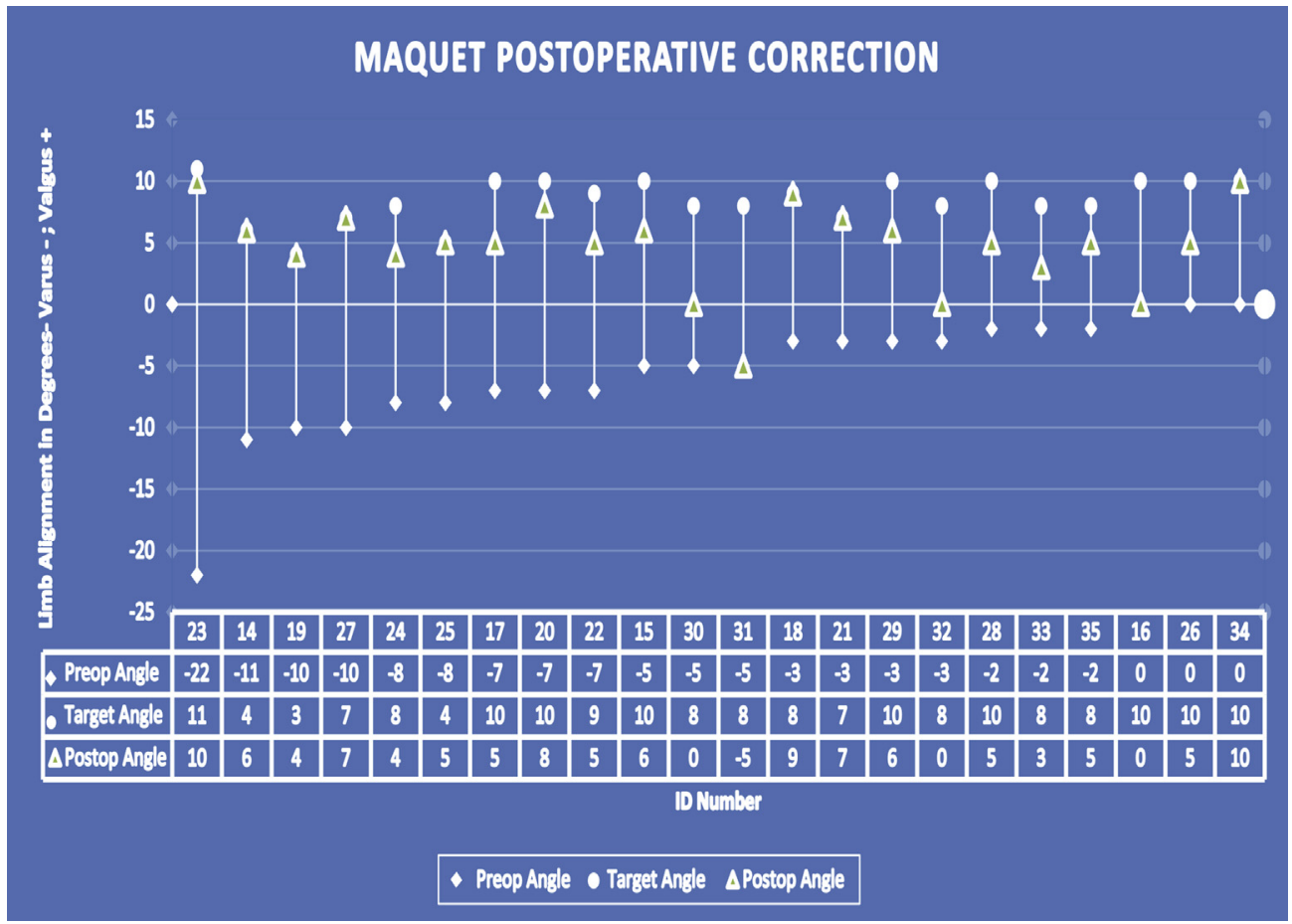

Fig 3. Maquet postoperative correction. Tibial osteotomies performed using the Maquet technique. Target angle, the prospectively planned valgus angle. Preop and postop angles, the angles measured on the preoperative and postoperative radiographs.

postoperative angle averaged $5.7^{\circ}$ of valgus (range $-5^{\circ}$ to $\left.14^{\circ}\right)$. There were 5 knees that were overcorrected by an average of $2.6^{\circ}$ (range $1^{\circ}-6^{\circ}$ ). No knees were corrected to exactly the target angle, and 16 knees were undercorrected by an average of $1.9^{\circ}$ (range $-1^{\circ}$ to $\left.-12^{\circ}\right)$. One patient had an increase in preoperative varus alignment after surgery by $2.0^{\circ}$ (ID \#5). Overall, 7 of $21(33.4 \%)$ of the knees were corrected to within \pm $2^{\circ}$ of the target angle.

In the 13 male knees (Fig 5), the preoperative angle averaged $-5.5^{\circ}$ (i.e., $5^{\circ}$ of varus range, $22^{\circ}$ of varus-to-neutral alignment). The target angle in
Fig 4. Female postoperative correction. Tibial osteotomies performed in females. Target angle, the prospectively planned valgus angle. Preop and postop angles, the angles measured on the preoperative and postoperative radiographs.

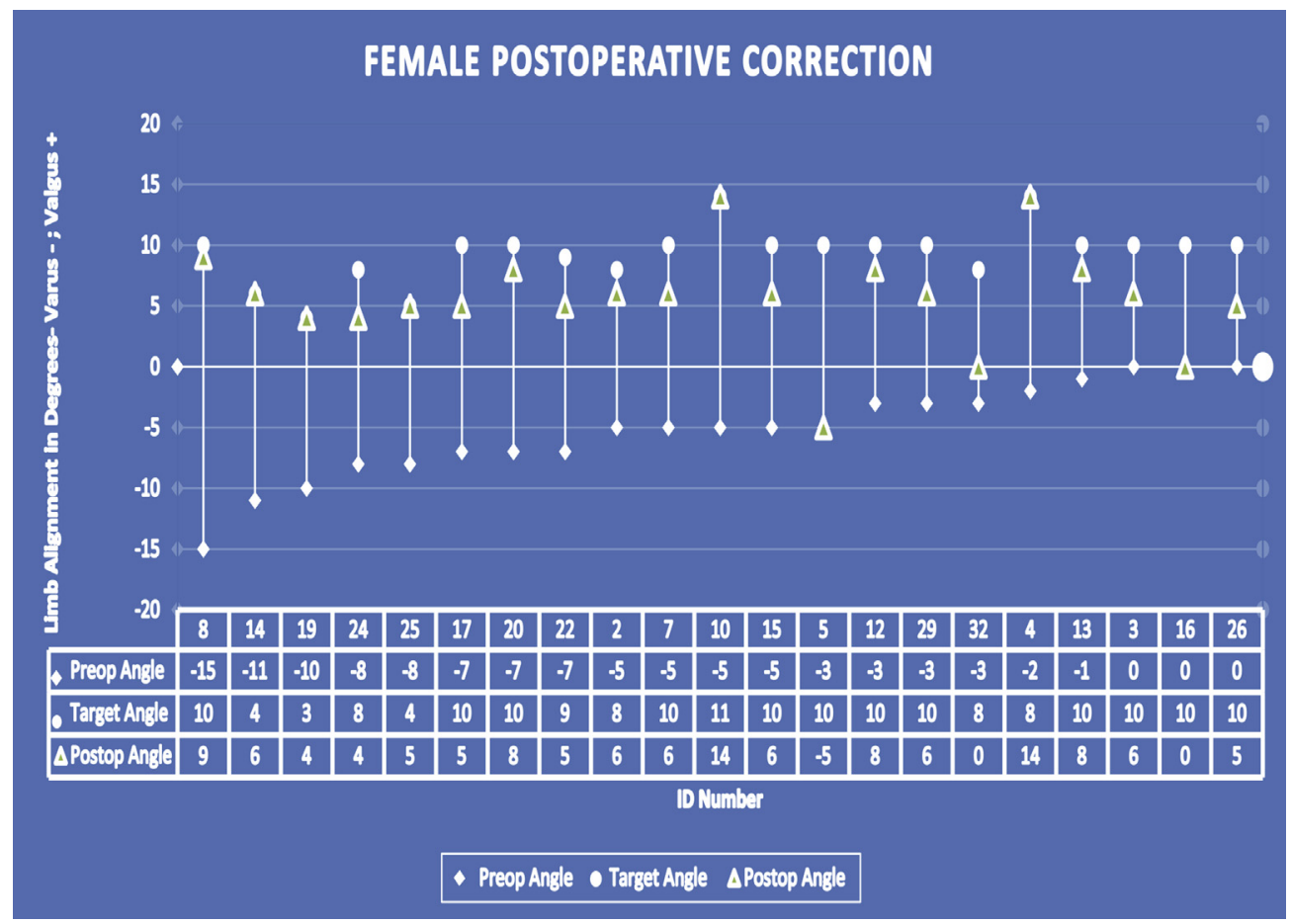




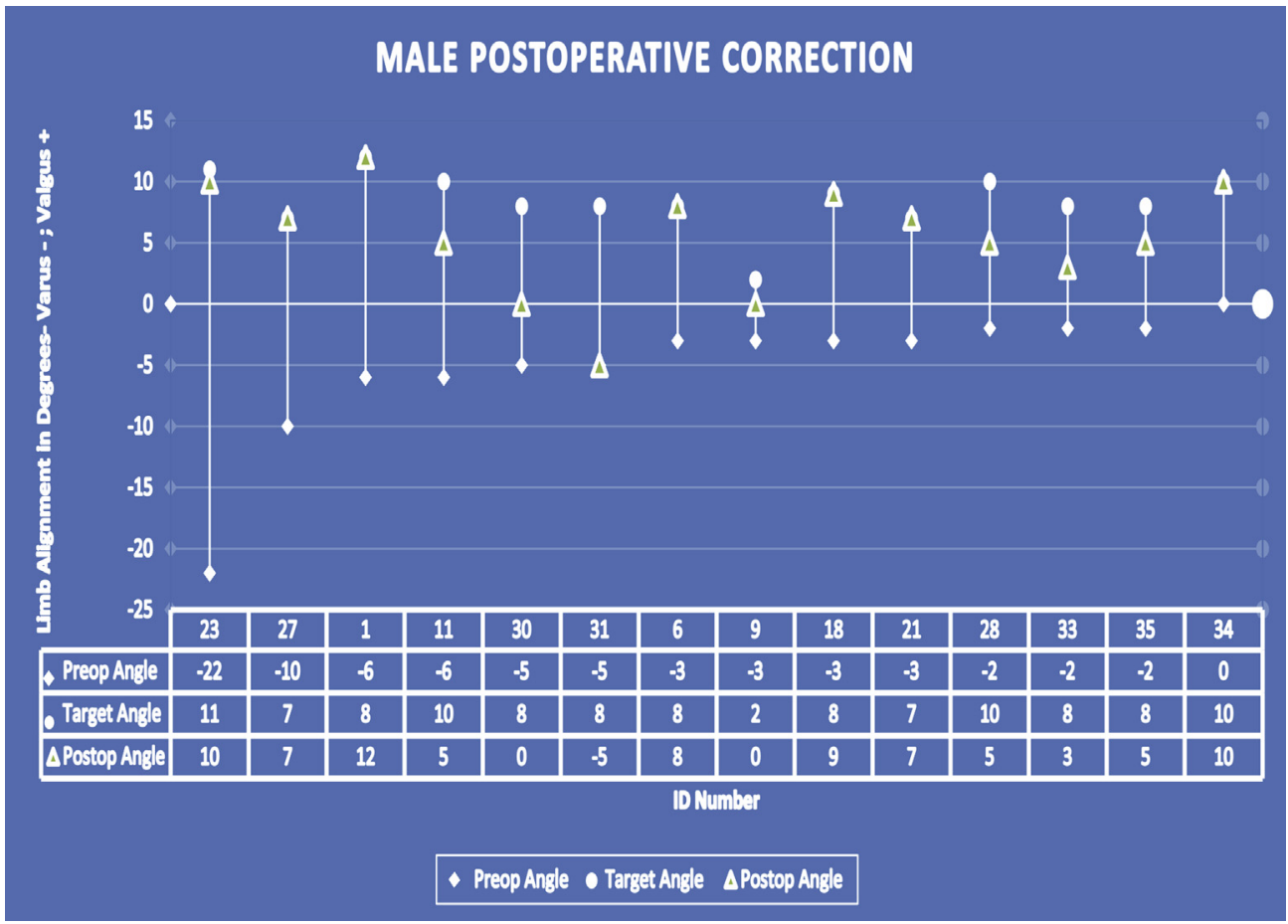

Fig 5. Male postoperative correction. Tibial osteotomies performed in males. Target angle, the prospectively planned valgus angle. Preop and postop angles, the angles measured on the preoperative and postoperative radiographs.

13 knees averaged $8.7^{\circ}$ (range $2^{\circ}-11^{\circ}$ of valgus). The planned correction averaged $13.8^{\circ}$ (range $5^{\circ}-25^{\circ}$ ). The postoperative angle averaged $5.8^{\circ}$ of valgus (range $-5^{\circ}$ to $13^{\circ}$ ). There were 2 knees that were overcorrected by an average of $4.5^{\circ}$ (range $\left.4^{\circ}-5^{\circ}\right), 3$ knees that were corrected to exactly the target angle and 8 knees that were undercorrected by an average of $8.5^{\circ}$ (range $-1^{\circ}$ to $\left.-3^{\circ}\right)$. No patient had an increase in preoperative varus alignment after surgery. Overall, 6 of $13(46.2 \%)$ of the knees were corrected to within $\pm 2^{\circ}$ of the target angle.

None of the demographic, radiographic or surgical technique factors in this study achieved statistical significance. Although the individuals (ID \#32 and \#34) with the 2 largest BMIs were poorly corrected by Maquet osteotomies, there was no apparent effect of BMI on the rest of the individuals (Fig 6).

A reliability study was performed by comparing the angular measurements obtained by the senior surgeon compared to blinded reviewers AM and SE. The average measurement difference among the reviewers was $1.2^{\circ}$ on the preoperative radiographs and $1.5^{\circ}$ on the postoperative radiographs.

\section{Discussion}

Our study showed that the ability to surgically achieve a specific target angle within $\pm 2^{\circ}$ in a specific
Fig 6. Postoperative correction by body mass index (BMI). Osteotomies sorted by highest to lowest BMI. Target angle, the prospectively planned valgus angle. Preop and postop angles, the angle measured on the preoperative and postoperative radiographs.

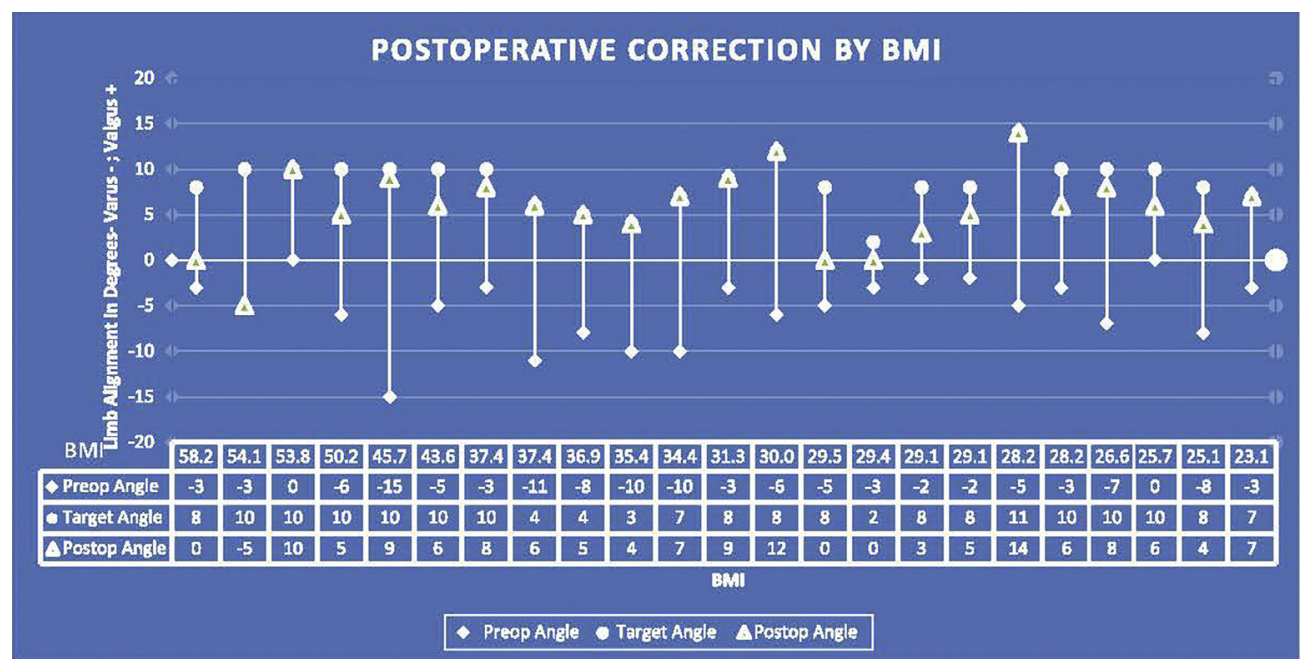


patient was successful in less than $40 \%$ of the patients. Surgical technique, BMI and gender had no apparent effect on the accuracy. Recommended target angles in the literature have generally been $2^{\circ}-3^{\circ}$ of mechanical valgus or $7^{\circ}-10^{\circ}$ of anatomic valgus (Table 1$) .{ }^{1-20}$ Alignment based on $62.5 \%$ of the width of the proximal tibia has been shown to be equivalent to $3^{\circ}$ of mechanical valgus alignment. ${ }^{16}$ The original method of determining the target angle was the " $1 \mathrm{~mm}$ per $1^{\circ}$ of correction" advocated by Coventry, ${ }^{3}$ which ignored simple geometry regarding the width of the tibia. Dugdale $^{16}$ also documented that the length of the tibia and femur as well as an increase in the lateral joint line (i.e., the stretch of the lateral side structures) also could affect the weightbearing axis and, therefore, could affect bony angular measurements. Brower ${ }^{19}$ found that neither isolated knee flexion or leg rotation without knee flexion changed the alignment axis, but simultaneous flexion and rotation had a large effect on the alignment.

Several surgical techniques based primarily on preoperative radiographs have been advocated. Historically, the closing wedge osteotomy popularized by Coventry $^{3}$ (and, more recently, the opening wedge and combination opening/closing wedge) has been advocated. Because weightbearing radiographs are obviously not possible in the operating room, several methods have been used to determine the intraoperative correction. Goniometers, metal rods, the Bovie cord method, radiograph-based templates, and correction in the postoperative period with external fixation devices have all been used. However, any method dependent on external landmarks may encounter intraoperative difficulties, especially in the obese and in individuals with deformities.

Various aspects of knee alignment and tibial osteotomies have been studied. Specogna ${ }^{24}$ stated that plain radiographs and digital radiographs were equally accurate in determining alignment. Odenberg ${ }^{25}$ stated that there was excellent reliability in the interobserver determination of alignment on plain radiographs (a maximum of $2^{\circ}$ ). However, he studied only 8 radiographs. Several authors have reported that the reproducibility of standing radiographs is poor. ${ }^{25-27}$ Schmidt ${ }^{26}$ stated that the accuracy of measurement by 2 reviewers in 30 asymptomatic individuals with a goniometer was $1^{\circ} \pm 0.5^{\circ}$, and full-length weightbearing radiographs were no more accurate than standard 14" $\times 17$ " anteroposterior film. Our own reliability study confirmed equivalence accuracy.

Ilahi ${ }^{27}$ found an average disagreement of $3.7^{\circ}$ (and a maximum of $6^{\circ}$ ) among 4 reviewers measuring the alignment on 36 radiographs. Ogata ${ }^{28}$ recommended supine radiographs, as opposed to weightbearing radiographs, and stated that weightbearing radiographs did not correlate well with the postoperative correction.
Sabharwal ${ }^{29}$ stated that there was an average of $18^{\circ}$ of difference between preoperative weightbearing films and operative fluoroscopy when he used the Bovie cord method, and he did not recommend this method in the obese. Bae ${ }^{18}$ stated that the computer navigation was more accurate than conventional instrumentation in achieving the mechanical axis, but there was only a $1.5^{\circ}$ difference between the 2 methods, which may not have been clinically significant. In his follow-up study in 2016, $\mathrm{Bae}^{30}$ stated that there was no difference in clinical results between computer navigation and conventional instrumentation

Our ability to achieve the target angle accurately on the basis of standing radiographs was unpredictable (i.e., less than half of the patients in our series $(40.0 \%, 14 / 35)$ were corrected to within $\pm 2^{\circ}$ of the target angle). None of the factors studied in our series consistently correlated with the ability to achieve the planned target angle. Two patients (ID \#30 and ID \#34) had only $50 \%$ corrections on the standing films, but valgus stress radiographs showed $90 \%$ of the target angle, which would seem to indicate that the planned angular bony correction was largely achieved at surgery, but either we did not plan sufficient correction or the correction actually achieved was not sufficient to statically unload the medial compartment and reestablish standing static valgus alignment on radiographs. It is our opinion that the inability to achieve consistently the planned correction according to weightbearing radiographs is probably multifactorial.

The amount of correction necessary to unload the medial compartment dynamically is not known. Sundaram ${ }^{31}$ stated that there was no correlation between the correction of the deformity to physiologic valgus and the clinical results. Prodromas ${ }^{32}$ stated that patients with tibial osteotomy and low adduction moments preoperatively did much better after tibial osteotomy than patients with high adduction moments, and he stated that static alignment did not directly correlate with dynamic joint alignment. Shaw ${ }^{33}$ also offered a somewhat similar theory, opining that because the mechanical axis of the entire body in a single leg stance while walking is actually somewhat medial to the knee itself; correction according to the mechanical or anatomic axis of the limb may not be equivalent to the true weight-bearing line of the body's center of gravity and may not be sufficient to shift the weightbearing dynamically from the degenerated medial to the lateral compartment. Ramsey ${ }^{34}$ noted that the muscle and gait compensation typical of patients with osteoarthritis were only partially corrected, even after apparently clinically successful opening wedge tibial osteotomy. We also cannot comment on the maintenance of correction over time. Although none of the patients in this series had opening wedge osteotomies, Lee ${ }^{35}$ stated 
that gradual loss of correction can occur with opening wedge osteotomies for up to 1 year, which could contribute to clinical failure even though the initial correction was "adequate."

Future studies with computer navigation may achieve more accurate boney correction, but much larger series with longer term follow-up will be required to substantiate clinical utility. Static weightbearing radiographs may not correlate with the dynamic forces involved in walking. Therefore, achieving any specific static alignment may not be a critical issue in valgus tibial osteotomies. Perhaps, single-leg weight-bearing radiographs or gait analysis would more accurately depict the weightbearing forces of walking.

\section{Limitations}

The surgical planning was prospective, but this was not a consecutive series because we did not have complete postoperative standing radiographs for every osteotomy done during the study's timeframe. Obviously, this is a single-surgeon series, which risks bias, but the radiographs were measured by staff not involved in the surgery. We cannot confirm or deny the literature's target-angle recommendations because this study was limited to a radiologic analysis. We also cannot extrapolate these results to other valgus high tibial osteotomy techniques (i.e., opening wedge) but because this was a radiographic evaluation, we would anticipate similar results with similar radiographic evaluations of other surgical techniques.

\section{Conclusions}

Valgus tibial osteotomy planning based on preoperative weight-bearing radiographs is unpredictable in its ability to achieve the target angle for postoperative weight-bearing radiographs. Overall, only $40 \%$ of our patients were corrected to within $\pm 2^{\circ}$ of the planned target angle. The tendency was to undercorrect using either the Coventry or the Maquet technique. Contrary to our hypothesis, larger preoperative varus alignment (greater than $10^{\circ}$ varus alignment) did not make it more difficult to achieve the target angle. The Coventry technique was as accurate as the Maquet technique.

\section{References}

1. Shoji H, Insall J. High tibial osteotomy for osteoarthritis of the knee with valgus deformity. J Bone Joint Surg Am 1973;55:963-973.

2. Insall J, Joseph DM, Miska C. Tibial osteotomy for varus gonarthrosis. J Bone Joint Surg Am 1984;66:1040-1048.

3. Coventry MB, Ilstrup D, Wallrichs S. Proximal tibial osteotomy: A critical long-term study of 87 cases. J Bone Joint Surg Am 1993;69:196-201.

4. Akamatsu Y, Kosino T, Saito T, Wade J. Changes in osteosclerosis of the osteoarthritic knee after high tibial osteotomy. Clin Orthop Relat Res 1997;274:207-214.
5. Aglietti P, Buzzi R, Vena LM, et al. High tibial valgus osteotomy for medial gonarthrosis: Knee 10-21 year study. J Knee Surg 2003;16:21-26.

6. Sprenger TR, Doerzbacher JF. Tibial osteotomy for treatment of varus gonarthrosis: Survival and failure analysis for 22 years. J Bone Joint Surg Am 2003;85:469-474.

7. Koshino T, Yoshida T, Ara Y, et al. A 15-28 year follow-up of high tibial valgus osteotomy for osteoarthritis of the knee. Knee 2004;11:439-444.

8. Huang T, Tseng KF, Chen WM, et al. Preoperative tibiofemoral angle predicts survival of the proximal tibial osteotomy. Clin Orthop Relat Res 2005;432:188-195.

9. Flecher X, Parrattte S, Aubaniac JM, Argenson JN. A 1228 year follow-up of closing wedge high tibial osteotomy. Clin Orthop Relat Re 2006:452:91-96.

10. Puddu G, Cipolla M, Cerullo G, et al. Osteotomies: The surgical treatment of the valgus knee. Sports Med Arthrosc Rev 2007;15:5-22.

11. Akizuki S, Shibakawa A, Takizawa T, et al. The long-term outcome of high tibial osteotomy. J Bone Joint Surg $\mathrm{Br}$ 2008;90:592-596.

12. Howells NR, Salmon L, Wallwe A, et al. The outcome at 10 years of lateral closing wedge high tibial osteotomy: Determinants of survival and functional outcome. J Bone Joint Surg Br 2014;96:1491-1497.

13. Maquet P. Valgus osteotomy for osteoarthritis of the knee. Clin Orthop Relat Res 1976;120:143-148.

14. Krempen JF, Silver RA. Experience with the Maquet barrel vault osteotomy. Clin Orthop Relat Res 1982;168:86-96.

15. Brouwer RW, Bierma-Zeinstra SMA, van Raaij TM, Verhaar JAN. Osteotomy for medial compartment arthritis of the knee using a closing wedge or opening wedge controlled by a putting plate: A 1-year randomized, controlled study. J Bone Joint Surg Br 2006;88: 1454-1459.

16. Dugdale TW, Noyes FR, Styer D. Preoperative planning for high tibial osteotomy: The effect of the lateral tibial femoral separation and tibiofemoral length. Clin Orthop Relat Res 1992;274:248-264.

17. Aoki Y, Yasuda K, Mikami S, et al. Inverted V-shaped high tibial osteotomy compared with closing wedge high tibial osteotomy for osteoarthritis of the knee. J Bone Joint Surg Br 2006;88:1336-1340.

18. Bae DK, Song SJ, Yoon KH. Closed wedge high tibial osteotomy using computer-assisted surgery compared to the conventional technique. J Bone Joint Surg Br 2009;91: 1164-1171.

19. Lee D, Hha KW, Park SJ, Han SB. Preoperative and postoperative comparisons of navigation and radiologic limb alignment measures after high tibial osteotomy. Arthroscopy 2012;28:366-372.

20. Kondo E, Kazunori Y, Yabuuci K, et al. Inverted V-shaped Tibial osteotomy for medial osteoarthritic knees with severe varus deformity. J Arthrose Tech 2018;7: e999-e1012.

21. Miller GK. The barrel vault osteotomy of Maquet. J Arthrosc Tech 2019;8:e793-e800.

22. McGrory JE, Trousdale RT, Pagnano MW, Nigbur M. Preoperative hip to ankle radiographs and total knee arthroplasty. Clin Orthop Relat Res 2002;404:196-202. 
23. Alzahrani MM, Wood TJ, Somerville LE, et al. Correlation of short knee radiographs and full-length radiographs in patients undergoing total knee arthroplasty. J Am Acad Orthoped Surg 2019;27:e516-e521.

24. Specogna AV, Birmingham TB, DaSilva JB, et al. Reliability of lower limb and frontal plane alignment measurement using plain radiographs and digitized images. J Knee Surg 2004;17:203-210.

25. Odenbring S, Berggren A, Peil L. Roentgenographic assessment of the hip-knee-ankle axis and medial gonarthrosis: A study of reproducibility. Clin Orthop Relat Res 1993;289:195-196.

26. Schmidt GL, Altman GT, Dougherty JJT, DeMeo PJ. Reproducibility and reliability of the anatomic axis of the lower extremity. J Knee Surg 2004;14:238-242.

27. Ilahi OA, Kadakia NR, Huo MH. Interobserver and intraobserver variability of radiographic measurements of knee alignment. Am J Knee Surg 2001;14:238-242.

28. Ogata K, Yoshi Y, Kawamura H, et al. Standing radiographic radial cannot determine the correction in high tibial osteotomy. J Bone Joint Surg Br 1991;73:927-931.

29. Sabharwal S, Zhao C. Assessment of lower limb alignment: Supine fluoroscopy compared with the standing full-length radiograph. J Bone Joint Surg Am 2008;90: 43-51.

30. Bae DK, Song SJ, Kim KI, et al. Midterm survival analysis of closed wedge high tibial osteotomy: A comparison study of computer-assisted surgery compared to the conventional technique. Knee 2016;23:283-288.

31. Sundarem NA, Hallett JP, Sullivan MF. Dome of osteotomy of the tibia for osteoarthritis of the knee. J Bone Joint Surg Br 1986;68:782-786.

32. Prodromos CC, Andriachi TP, Galante JO. A relationship between gait and clinical changes following high tibial osteotomy. J Bone Joint Surg Am 1985;67:1 188-1194.

33. Shaw JA, Moulton MJ. High tibial osteotomy: An operation based on a spurious mechanical concept: A theoretical treatise. Am J Orthoped 1996;25:429-436.

34. Ramsey DK, Snyder-Macler L, Lewek M, et al. Effect of anatomic realignment and muscle function during gait in patients with medial compartment osteoarthritis. Arthrit Rheumat 2007;57:389-397.

35. Lee YS, Lee BK, Kwon JH, et al. Serial assessment of weightbearing lower extremity alignment radiographs after open wedge high tibial osteotomy. Arthroscopy 2014;30:319-325. 